\title{
Duodenal bulb tumour of unknown origin
}

\author{
Karolina Hankiewicz-Ziołkowska ${ }^{1}$, Marcin Soboń ${ }^{1}$, Tadeusz Szylberg ${ }^{2}$, Janusz Rudziński ${ }^{1}$ \\ ${ }^{1}$ Department of Clinical Gastroenterology, $10^{\text {th }}$ Military Hospital with Policlinic, Bydgoszcz, Poland \\ ${ }^{2}$ Department of Pathology, $10^{\text {th }}$ Military Hospital with Policlinic, Bydgoszcz, Poland
}

Prz Gastroenterol 2014; 9 (6): 365-370

DOI: $10.5114 / p g .2014 .47900$

Key words: gastrointestinal stromal tumours, tumour, duodenal bulb.

Address for correspondence: Karolina Hankiewicz-Ziołkowska MD, Department of Clinical Gastroenterology, $10^{\text {th }}$ Military Hospital with Policlinic, 5 Powstańców Warszawy St, 85-681 Bydgoszcz, Poland, phone: +48 666851 677, e-mail: hankiewicz_k@wp.pl

\begin{abstract}
Gastrointestinal stromal tumours (GIST) are rare mesenchymal neoplasms of the gastrointestinal tract. Their development typically depends on mutations in the Kit or PDGFRA gene. We have diagnosed and treated a duodenal bulb GIST in a 63-yearold woman. The confirmation of the diagnosis was made on the basis of a histological test after radical resection of the tumour. Making the right diagnosis is crucial for patients, since complex surgical and pharmacological approaches are effective even in the advanced stages of the disease. Nevertheless, radical surgical treatment is still the primary choice for patients with GIST.
\end{abstract}

\section{Introduction}

Gastrointestinal stromal tumours (GIST) or stromal tumours are rare gastrointestinal tract tumours. They represent $0.1-3 \%$ of all gastrointestinal neoplasms and can occur at any place within the gastrointestinal tract [1-4]. Until recently, stromal tumours have been described as a leiomyomas, leiomyosarcomas, or leiomyoblastomas $[5,6]$. Schaldenbrand and Appelman introduced the term "stromal tumour" in 1984 to define a subset of mesenchymal tumours referred to by several definitions concerning neurogenic or myogenic differentiation [7]. It is widely believed that GIST originate from, or are closely related to, the interstitial cells of Cajal precursors that are responsible for coordinated muscle contraction of the gastrointestinal tract [1]. The tumour is the result of mutations in the genes encoding the KIT membrane receptor (V-Kit Hardy-Zuckerman 4 Feline Sarcoma Viral Oncogene Homolog) or PDGFRA (alpha-type platelet-derived growth factor receptor, platelet-derived growth factor receptor alpha) $[8,9]$ The consequence of the c-kit proto-oncogene mutation is a membrane receptor protein expression of c-kit (CD117), a tyrosine kinase, which is present in $85-100 \%$ of GIST [10]. CD34 antigen is also positive by immunohistochemistry in $60-70 \%$ of GIST cases. The absence of this antigen is considered an indicator of non malignancy $[11,12]$. KIT mutations responsible for the development of stromal tumours occur in exons $9,11,13$, and
17 and are of a single mutation. Mutation in exon 11 is associated with a better response to imatinib (a selective tyrosine kinase inhibitor) than the mutation in exon 9 [13-15]. The PDGFRA mutations occur in exons 12, 14, and $18[13,14]$. In $5 \%$ of stromal tumours no mutations were observed, suggesting that GIST histogenesis does not always correspond to mutations $[16,17]$.

The GIST tumours can occur in people of any age, but most patients (75\%) with GIST are over 50 years old [18]. Stromal tumours are more common in men [13]. Although the vast majority of GISTs are sporadic, rare familial forms have been described $[1,13]$. Family-observed GIST occur in patients with neurofibromatosis type 1 , and in the case of Carney triad, a rare syndrome defined by the simultaneous occurrence of gastric stromal sarcoma, pulmonary chondroma and extra-adrenal paraganglioma $[1,19]$.

The GIST location in the gastrointestinal tract accounts for about $90 \%$ of all stromal tumours $[1,11]$. The most common locations of GIST are the stomach (40$70 \%$ ), small intestine (20-50\%), colon (around 5\%), and oesophagus $(<5 \%)[1,13,18]$. Other less common locations are those outside of the gastrointestinal tract, like mesentery, retroperitoneum, and omentum. However, rare cases have been reported in the gallbladder, pancreas, liver, and urinary bladder. In cases where GIST occurs outside the gastrointestinal tract, the tumours are known as extra-gastrointestinal stromal tumours (EGISTs) [1]. 
Stachura et al. [10] estimate that in Poland there are 400-700 new cases of GIST each year. Symptomatic stromal tumours located in the duodenum are extremely rare. Usually the first symptom is an abnormal resistance in the abdominal cavity detected during palpation $[18,20]$. In patients with advanced tumours the first symptom can be an acute bleeding from the upper gastrointestinal tract $[18,20]$. Very often, however, patients report symptoms such as abdominal pain, abdominal distension, fatigue, and anaemia [21, 22]. Small asymptomatic lesions in the duodenum may be found incidentally during esophagogastroduodenoscopy, computed tomography, or exploratory laparotomy performed for other indications [5, 18, 23].

The primary treatment for GIST is a local radical surgery without removal of unchanged lymph nodes, which in the case in tumours; giving no distant metastases remains the "gold standard" $[8,17,24]$. The GIST tumours, in approximately $35-40 \%$ of cases, are characterised by a high risk of recurrence after primary surgery, and approximately $30 \%$ of stromal tumours show features of malignancy with evidence of invasion and metastasis formation in the peritoneum and liver [11].

Previous studies have shown that survival depends on the size of the tumour and microscopic characteristics.

\section{Case report}

A 63-year-old woman, without previous family history of cancer, was admitted to the Clinical Department of Gastroenterology, $10^{\text {th }}$ Military Clinical Hospital in Bydgoszcz, Poland, for diagnosis of unknown duodenal bulb tumour, identified in an ambulatory esophagogastroduodenoscopy. The patient reported a burning sensation in the oesophagus, regardless of accepted meals, with no improvement after treatment with a proton pump inhibitor. The patient denied abdominal pain, weight loss, fatigue, lack of appetite, tarry stools, or bloody vomiting. Medical history revealed hypertension, hypothyroidism, and bronchial asthma.

The patient was in good condition at the day of admission to the hospital. Her heart rate was $80 \mathrm{bpm}$, and arterial blood pressure was 160/80 mm Hg. Lung auscultation indicated normal vesicular murmur without evidence of pulmonary obstruction or stagnation. The abdomen was painless in palpation, she had non-enlarged liver and spleen, normal peristalsis, and no perceptible pathological resistance in the abdominal cavity in palpation.

Laboratory tests (blood cell count, ionogram, total bilirubin, glucose, creatinine, transaminases, thyroid hormones, markers CEA, AFP, Ca19.9) performed during hospitalisation gave results without deviations from accepted laboratory standards.

Ambulatory esophagogastroduodenoscopy revealed a polypoid change in the duodenum, $15 \mathrm{~mm} \times 10 \mathrm{~mm}$ in diameter, narrowing the light of the intestine. Another esophagogastroduodenoscopy performed during hospitalisation confirmed the presence of a duodenal bulb tumour on the rear wall and the upper curve of the duodenum, $20 \mathrm{~mm} \times 15 \mathrm{~mm}$ in diameter, raised to about $10 \mathrm{~mm}$, with a lesion in the top, $6 \mathrm{~mm} \times 8 \mathrm{~mm}$ in diameter, filled with inflammatory granulation tissue with visible, translucent, spontaneously bleeding vessels (Figures 1 A-D).

Tissue samples were taken for histopathological examination, which showed inflammatory granulation tissue. Abdominal computed tomography revealed a solid nodular change in the duodenal bulb, $19 \mathrm{~mm} \times 18 \mathrm{~mm}$ $\times 24 \mathrm{~mm}$ in diameter, emanating from the medial wall of the duodenal bulb, and the signal strengthened significantly after intravenous administration of contrast medium (Figures 2 and 3).

After surgical consultation due to spontaneous bleeding from the tumour, the patient was qualified for elective surgery and submitted to the Department of Surgery, $10^{\text {th }}$ Military Hospital.

Intraoperatively a tumour was found, measuring $20 \mathrm{~mm} \times 20 \mathrm{~mm} \times 30 \mathrm{~mm}$, located around the top bend on the rear-side of the duodenum, penetrating toward the ampulla of Vater. An intraoperative histopathological examination of the tumour was performed. Microscopic examination revealed the presence of malignant cells. Local excision was performed, followed by resection of the duodenum and the upper distal part of the stomach. The duodenal papilla of Vater was closed above. Gastrointestinal continuity was restored by Roux-Y. Regional lymph nodes in the intraoperative study were unchanged. After the procedure, the patient was transferred for 2 days to the Postoperative Intensive Care Unit in the $10^{\text {th }}$ Military Hospital. She was then transferred once more to the Department of Surgery of the $10^{\text {th }}$ Military Hospital. The postoperative course was uneventful. The patient in the eleventh postoperative day was in good condition and was discharged from hospital was referred for further cancer care to the Oncology Centre in Bydgoszcz.

Histopathological examination of a duodenal wall fragment revealed a solid, grey submucosal tumour, $25 \mathrm{~mm} \times 20 \mathrm{~mm}$ in diameter.

Macroscopically the examined part of the duodenum was $110 \mathrm{~mm}$ length and $50 \mathrm{~mm}$ wide, with normal mucosa and a submucosal tumour measuring $25 \mathrm{~mm} \times 20 \mathrm{~mm} \times 30 \mathrm{~mm}$. The surgical cutting line was without neoplastic infiltration. A fragment of body fat 

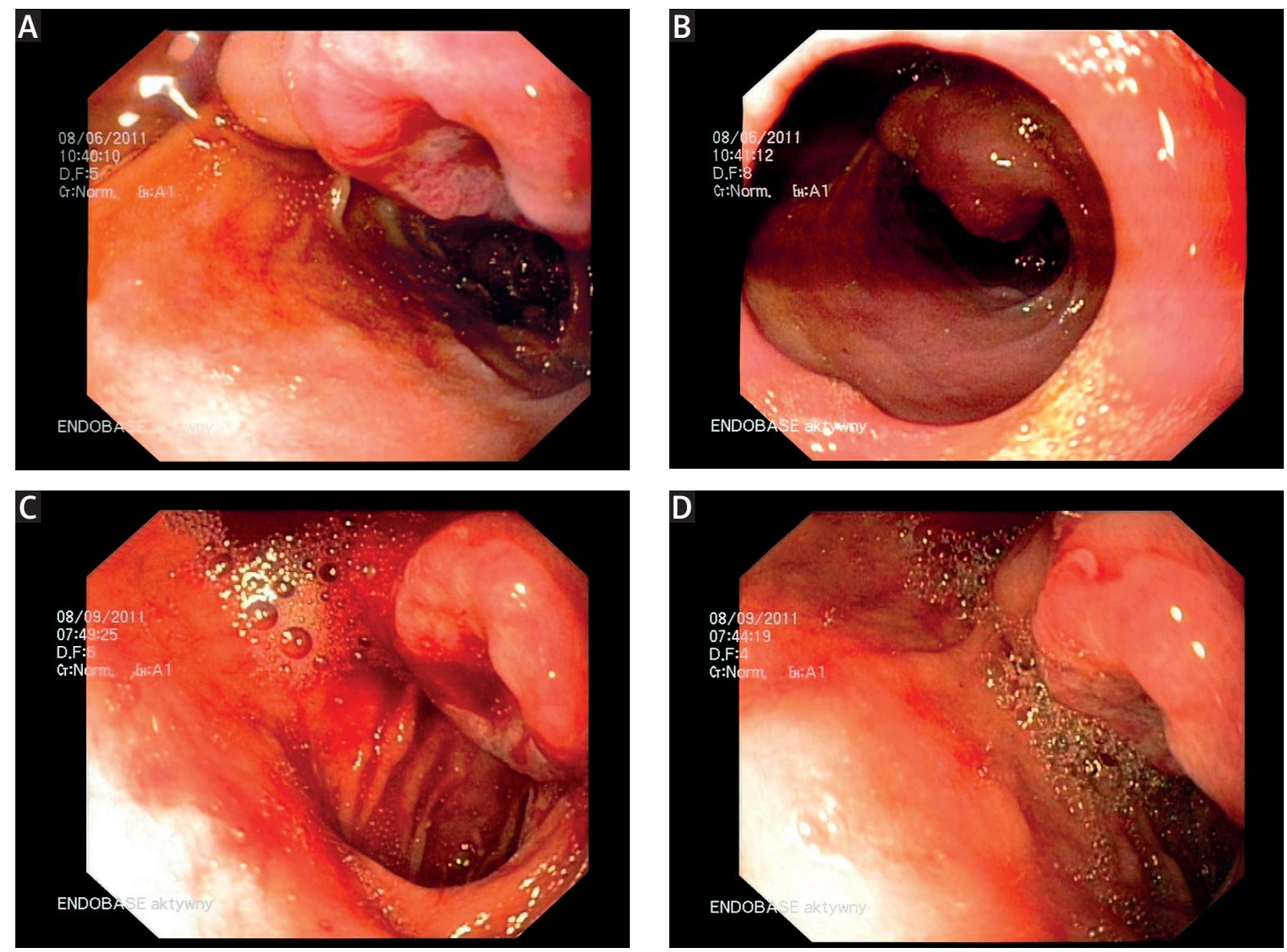

Figure 1 A-D. Duodenal bulb tumour with lesion in gastroduodenoscopy

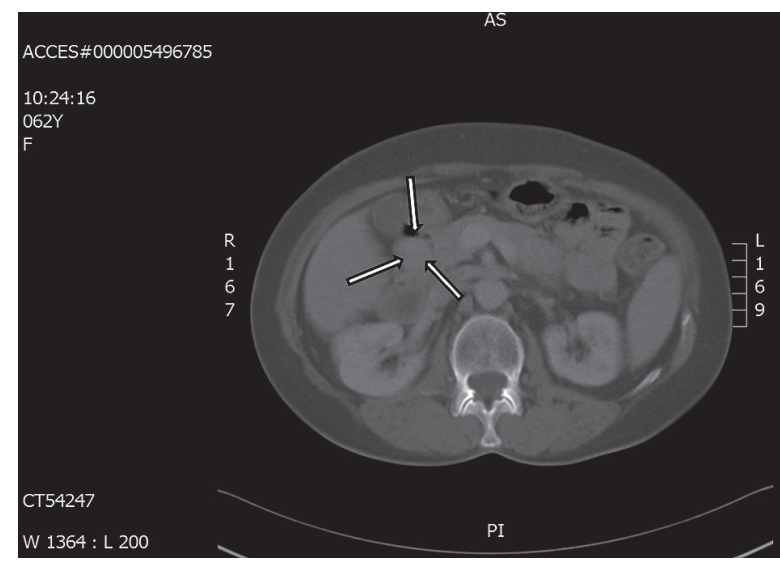

Figure 2. Duodenal bulb tumour (arrows) in computed tomography - sagittal projection

was tested, $80 \mathrm{~mm} \times 45 \mathrm{~mm}$ in diameter, without neoplastic infiltration. Sections of tissue were stained with haematoxylin and eosin ( $\mathrm{H}+\mathrm{E}$ staining).

The immune-histological chemistry staining of the tumour tissue samples demonstrated a strong expres-

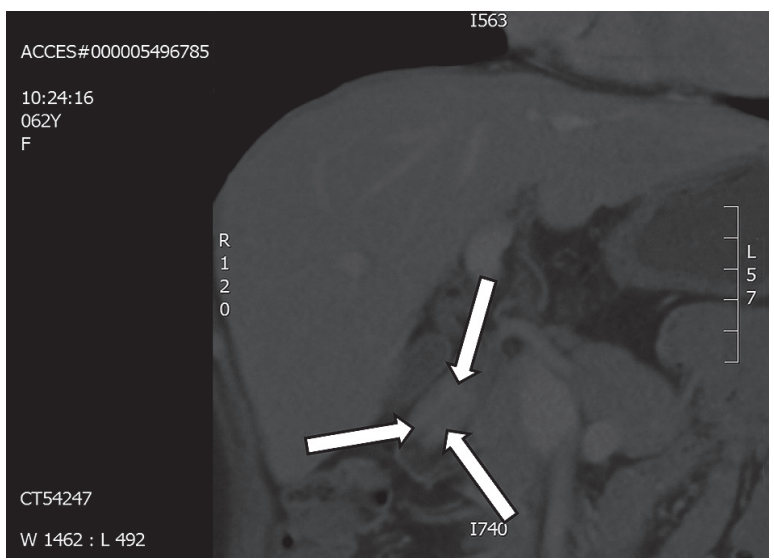

Figure 3. Duodenal bulb tumour (arrows) in computed tomography - frontal projection

sion of CD34 and CD117 and low mitotic index (Ki-67 $<2 \%$ ), with a breakdown of figures 6/50 HPF (high power field, a field with high magnification 400x). The tumour identified as GIST. Histopathological staining results are shown in Figures 4-6. 


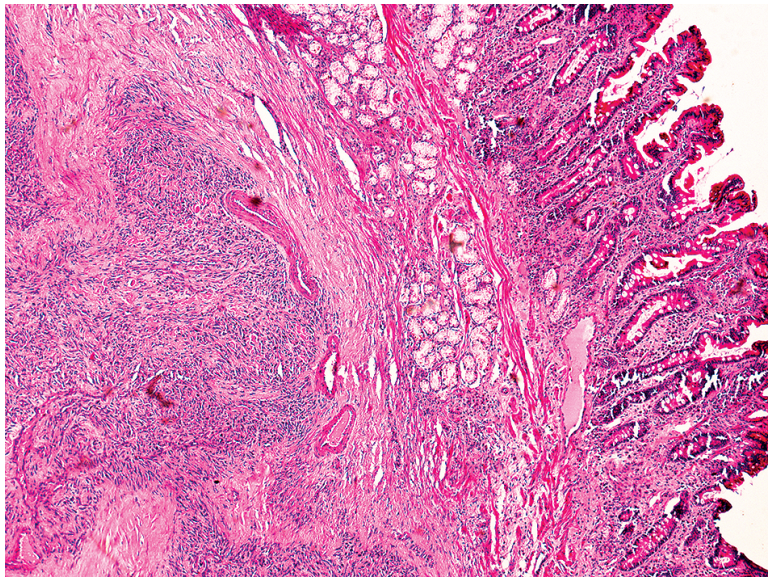

Figure 4. Duodenal GIST histology. $\mathrm{H}+$ E staining. Magnification 100x

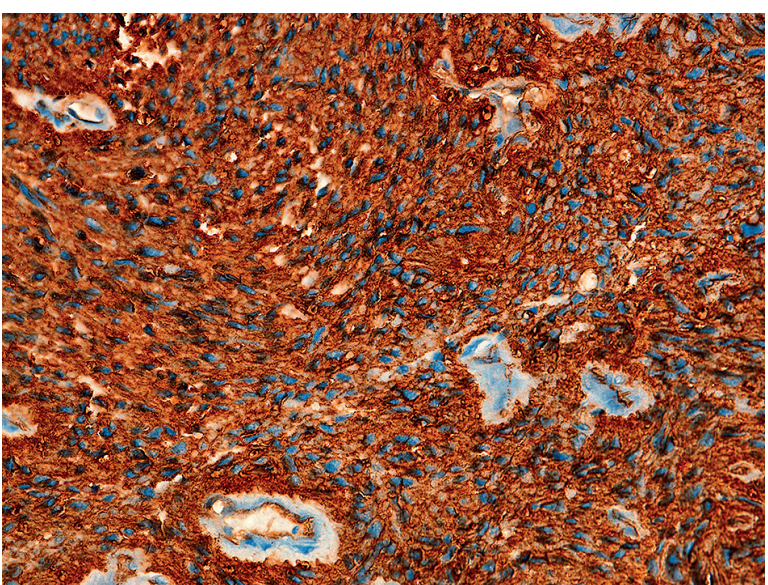

Figure 5. CD117-positive cells in GIST structure. Immunohistochemical staining. Magnification $200 x$

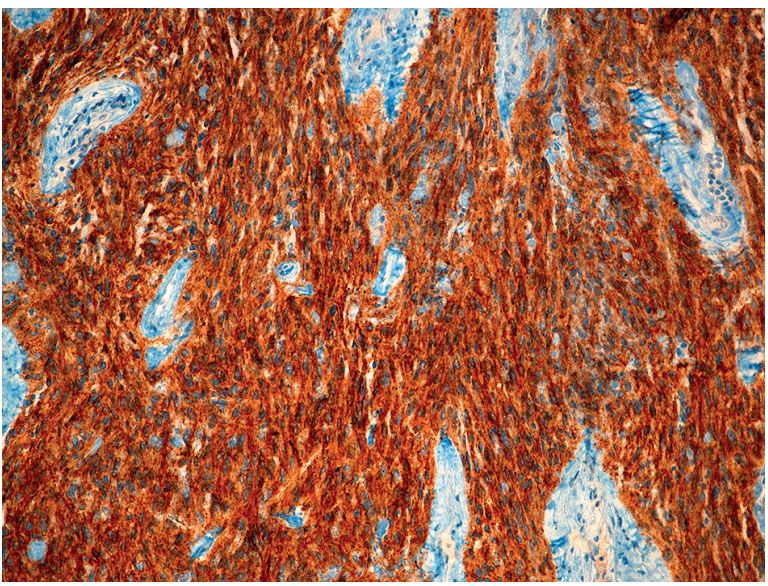

Figure 6. The GIST presenting CD-34 expression. Magnification 200x

\section{Discussion}

Gastrointestinal stromal tumours are the most common tumours of mesenchymal origin occurring within the abdominal cavity. Nonspecific symptoms of GIST and the difficulty of obtaining histological material due to subserous and submucous growth mean that they are usually diagnosed on the basis of the results of postoperative histopathological tissue sample examinations. The final diagnosis of GIST needs to be confirmed with immunostaining and/or molecular detecting mutations in the Kit and PDGFRA genes. As proposed by the National Institute of Health $(\mathrm{NIH})$, the division of GIST is distinguished by the degree of aggressiveness of tumours: very low, medium, and high aggressiveness. The term "mild" GIST is not in use [23]. This division includes the size of the tumour and the number of mitoses per 50 fields of view at high microscope magnification $(400 x)$. The location of the tumour, cellular atypia, tumour cellularity, and the presence of necrosis influence prognosis $[6,11]$. Tumours with a diameter greater than $10 \mathrm{~cm}$ are classified as high-grade tumours, and tumours with high mitotic activity greater than 10/50 of the field of view, regardless of the size of the tumour, have a high degree of tumour aggressiveness [11].

The most effective way of dealing with GIST is surgical resection [25]. Radical surgery gives 42-80\% 5-year survival, whereas non-radical surgery gives only 0-8\% 5-year survival [11]. In the case of intestinal localisation of GIST, segmental resection of the small intestine or hemicolectomy is performed. The literature states that lymphadenectomy is not justified, because lymph node metastases are rare $[26,27]$. It is important, however, to avoid damage during the operation of the tumour as it can lead to the intraperitoneal spread of tumour cells $[11,14]$.

Sákra et al. state that also a laparoscopic approach appears highly appropriate in most patients, especially in stomach GIST [28]. With small bowel GIST, laparoscopy allows the tumour to be located in order to perform minor laparotomy [28].

A large percentage of patients are those with incidental GIST. Incidentally detected gastrointestinal stromal tumours are usually small in size and are not visible in imaging studies. Gastroduodenoesophagoscopy, endoscopic ultrasound, and computed tomography with oral and intravenous contrast are most commonly used in the diagnosis of gastrointestinal stromal tumours. Due to the subserous and submucous location of stromal tumours, usually no adequate tissue samples are taken with standard biopsy forceps. In our case, GIST was confirmed with postoperative histopathological material.

In the treatment of inoperable or metastatic GIST, targeted therapy with imatinib, which is a selective in- 
hibitor of tyrosine kinases, is applied. In case of intolerance or resistance to imatinib treatment, sunitinib is the drug of choice $[3,9]$.

The recurrence rate of GIST is $40-80 \%$. Frequently relapse involves a local growth or liver metastases [11, 29]. It is believed that even after radical surgical treatment, imatinib should be used [11]

\section{Conclusions}

Stromal tumours are a heterogeneous group of mesenchymal neoplasms, with an unpredictable clinical course. Because of the heterogeneous cell structure, histological structure, and mitotic activity of polymorphic angiogenesis, it is important to analyse the numerous segments of the tumour at the border of the surgical cutting. The "Gold standard" in the diagnosis of GIST are immunohistochemical studies using a panel of antibodies: CD117, CD34, dog1, vimentin (mesenchymal cell marker), SMA (smooth muscle actin), desmin (a marker of muscle cells), proteins S100, and HMB45 [14].

Treatment for initial operational changes is radical surgery, and in the case of advanced disease process pharmacotherapy is used. In Poland imatinib is registered as the drug of choice.

Due to the risk of relapse, patients should be supervised. Such patients should have an abdominal CT scan performed every 3-4 months for the first 2 years after surgery, then every 6 months up to 5 years after surgery, and every year after 5 years of treatment [14]. In the case of GIST with a low risk of recurrence, tests should be performed once a year [14].

Gathering more information on the treatment of GIST and its results will enable the development of more precise rules for the assessment of stage and grade. We are still waiting for the results of phase II and III clinical trials on new drugs such as nilotinib, motesanib, everolimus, dasatinib, and sorafenib [3, 9].

\section{References}

1. Caterino S, Lorenzon L, Petrucciani N, et al. Gastrointestinal stromal tumours: correlation between symptoms at presentation, tumour location and prognostic factors in 47 consecutive patients. World J Surg Oncol 2011; 9: 13.

2. Schreiber-Fackla H, Bode-Leśniewska B, Frigerio S, et al. Primary monophasic synovial sarcoma of the duodenum with SYT/ SSX2 type of translocation. Hum Pathol 2007; 38: 946-9.

3. Shash E, Abdulla M. GIST: the past, the present and the future. Advances in Oncology. September 2010, Kair, Egipt.

4. Sripathi S, Rajagopal KV, Srivastava RK, et al. CT features, mimics and atypical presentations of gastrointestinal stromal tumour (GIST). Indian J Radiol Imaging 2011; 21: 176-81.

5. Banyś A, Wągrowska-Danilewicz M, Kordek K, et al. Left atrial and ventricular malignant cardiac tumour in a 62-year-old woman: a case report [Polish]. Kardiochir Torakochir Pol 2010; 7: 443-8.

6. Yildirim M, Yakan S, Doganavasargil B, et al. A rare cause of intestinal hemorrhage: stromal tumour of duodenum. Turk J Cancer 2004; 34: 1 63-5.

7. Sarma D, Rodrigues G, Parameshwarappa S, et al. Intestinal obstruction secondary to duodenal gastrointestinal tumour. Gastroenterology 2010; 1: 26.

8. Kitamura Y. Gastrointestinal stromal tumours: past, present and future. J Gastroenterol 2008; 43: 499-508.

9. Le Cesne A, Domont J, Blésius A, et al. Mutational analysis in gastrointestinal stromal tumours. Eur J Clin Med Oncol 2011; 3: 58-63.

10. Stachura J, Limon J, Ruka W, et al. Gastrointestinal stromal tumors [Polish]. Via Medica, Gdansk 2003.

11. Głuszek S, Rylski R, Kot M, et al. GIST - risk of recurrence and dissemination [Polish]. Prz Gastroenterol 2008; 3: 176-84.

12. Kwon SH, Cha HJ, Jung SW, et al. A gastrointestinal stromal tumour of the duodenum masquerading as a pancreatic head tumour. World J Gastroenterol 2007; 13: 3396-9.

13. Katić V, Dindić B, Živković V, et al. Morphological and immunocytochemical characteristics of stromal gastrointestinal tumours. Acta Medica Medianae 2010; 49: 58-64.

14. Rutkowski P, Kulig J, Krzakowski M, et al. Recommendations for diagnostics and therapy of gastrointestinal stromal tumors (GIST) in 2010 [Polish]. Onkol Prakt Klin 2010; 6: 181-94.

15. Sanfordand M, Scott LJ. Imatinib as adjuvant therapy for gastrointestinal stromal tumour. Drugs 2010; 70: 1963-72.

16. Heinrich MC, Rubin BP, Longley BJ, et al. Biology and genetic aspects of gastrointestinal stromal tumours: KIT activation and cytogenetic alterations. Hum Pathol 2002; 33: 484-95.

17. Yamaguchi U, Nakayama R, Honda K, et al. Distinct gene expression-defined classes of gastrointestinal stromal tumour. J Clin Oncol 2008; 26: 4100-8.

18. Galbfach PJ, Langner EB, Czapiński-Tuzikiewicz T, et al. Gastrointestinal stromal tumors [Polish]. Wiad Lek 2007; 60: 114-9.

19. Otto K, Agaimy A, Braun A, et al. Multifocal gastric gastrointestinal stromal tumours (GISTs) with lymph node metastases in children and young adults: a comparative clinical and histomorphological study of three cases including a new case of Carney triad. Diag Pathol 2011; 6: 52.

20. Wroński M, Cebulski W, Pawłowski W, Krasnodębski IW. Diagnostic difficulties in patients with gastrointestinal stromal tumour [Polish]. Prz Gastroenterol 2006; 1: 115-20.

21. Hompes D, Topal B, Ectors N, et al. Gastrointestinal stromal tumour of the duodenum: extreme presentation in two cases. Acta Chir Belg 2004; 104: 110-3.

22. Patil DT, Rubin BP. Gastrointestinal stromal tumour. Advances in diagnosis and management. Arch Pathol Lab Med 2011; 135: 1298-310.

23. Poultsides GA, Pappou EP, Bloom GP, et al. Hybrid resection of duodenal tumours. J Laparoend Adv Surg Tec 2011; 21: 603-8.

24. Panagiotakis G, Spiridakis K, Chatziioannou M, et al. Surgical treatment of gastrointestinal stromal tumour of jejunum. Hippokratia 2011; 15: 282-3.

25. Yang WL, Yu JR, Zhu KK, et al. Duodenal gastrointestinal stromal tumour: clinical, pathologic, immunohistochemical characteristics, and surgical prognosis. J Surg Oncol 2009; 100: 606-10. 
26. Liyanage C, Abeygunawardhana S, Kumarage S, et al. Duodenum-preserving local excision of a gastrointestinal stromal tumour. Hepatobiliary Pancreat Dis Int 2008; 7: 214-6.

27. Sakamoto Y, Yamamoto J, Takahashi H, et al. Segmental resection of the third portion of the duodenum for a gastrointestinal stromal tumour: a case report. Jpn J Clin Oncol 2003; 33: 364-6.

28. Sákra L, Šiller J, Vyhnálek P, Hácová M. Surgical treatment of gastric and small bowel gastrointestinal stromal tumours. Videosurgery Miniinv 2011; 6: 138-43.

29. Han D, Deneve J, Gonzalez RJ. Recurrence risk after resection of gastrointestinal stromal tumours: size is not all that matters... the consequences of rumor rupture. Am Surg 2012; 78: 74-9.

Received: 24.05.2012

Accepted: 8.02.2013 